\title{
CARTOGRAFIA DE LIVROS DIDÁTICOS COM TEORIAS MODERNAS DA MATEMÁTICA DO INSTITUTO DE MATEMÁTICA E FÍSICA DA UNIVERSIDADE FEDERAL DA BAHIA (1960-1968): UMA ANÁLISE HISTÓRICA
}

\author{
Thalia de Jesus Silva ${ }^{1}$; Eliene Barbosa Lima ${ }^{2}$ \\ 1. Bolsista PROBIC/UEFS, Graduanda em Licenciatura em Matemática, Universidade Estadual de Feira de Santana, \\ e-mail: thalia4997@outlook.com. \\ 2. Orientadora, Departamento DEXA, Universidade Estadual de Feira de Santana, e-mail: \\ $\underline{\text { elienebarbosalima@gmail.com }}$
}

PALAVRAS-CHAVE: Livro Didático; Modernização do Ensino de Matemática; História.

\section{INTRODUÇÃO}

No plano de trabalho aprovado no Edital PROBIC/UEFS $\mathbf{N}^{\circ} 01$ / 2017, que faz parte do projeto de pesquisa intitulado "As teorias modernas da matemática nos livros didáticos das instituições educacionais superiores e secundárias brasileiras e baianas", o objetivo foi analisar historicamente por meio de categorias a cartografia de livros didáticos com teorias modernas da matemática do Instituto de Matemática e Física da Universidade Federal da Bahia (1960-1968). Tais teorias modernas da matemática começaram ser constituídas no séc. XIX, por meio de uma série de transformações, mudanças, inovações, que afetaram, de um modo geral, a sua organização profissional, os seus fundamentos epistemológicos e metodológicos, a estruturação das suas subáreas de conhecimento, repercutindo principalmente nos resultados de sua produção do conhecimento (LIMA e DIAS, 2010a; 2010b; LIMA, 2012). Isso teve reflexos no âmbito do ensino secundário, onde houve uma segunda reformulação do ensino de matemática, que posteriormente ficou conhecida como Movimento da Matemática Moderna (MMM). O objetivo dessa reforma foi modificar os currículos do ensino de Matemática, introduzir novas reorganizações curriculares e novos métodos de ensino visando uma aproximação do ensino a nível superior. Em termos de modernização dos programas, pretendia-se com a reforma a inserção de novos temas, tais como o conceito de grupo, anel e corpo; teoria dos conjuntos; espaço vetorial e álgebra de Boole (GUIMARÃES, 2009). Conforme artigo, Silva e Oliveira (2018), no Seminário de Royaumont, coordenado por Marshall Stone8 (1903 - 1989), a proposta de reformulação do ensino de matemática foi contemplada pelas idéias estruturalistas, em especial da Matemática e da Psicologia. Dentre as propostas apresentadas a que mais se destacou foi a do Grupo Bourbaki ${ }^{1}$, o qual estava representado por um de seus membros, o matemático Jean Dieudonné (1906-1992).

\section{MATERIAL E MÉTODOS OU METODOLOGIA (ou equivalente)}

Para o desenvolvimento do plano de trabalho, foi feita a construção de novas categorias para serem inseridas em uma cartografia de livros didáticos com teorias modernas da matemática construída preliminarmente, no plano de trabalho aprovado no Edital PIBIC/CNPq, PIBIC/FAPESB E PROBIC/UEFS $\mathrm{N}^{\circ} 01$ / 2016. Tais livros foram apropriados, produzidos e difundidos no Instituto de Matemática e Física (IMF) da

\footnotetext{
${ }^{1}$ Fundado em 1935, o Grupo Bourbaki, foi formado em torno de um nome fictício, isto é, Nicholas Bourbaki. Seus membros fundadores, na grande maioria de nacionalidade francesa e preocupados em formar uma nova comunidade de matemáticos franceses, que havia sido dilacerada devido a Primeira Guerra Mundial, articularam o seu modelo matemático a partir de sua insatisfação com a obra clássica de análise matemática moderna de Edouard Goursat (1858-1936). (LIMA, 2012).
} 
Universidade Federal da Bahia (UFBA) no período de 1960 - ano de sua criação - a 1968 - quando foi criado seu Curso de Pós-Graduação em Matemática, ampliando, dessa forma, o acervo de sua Biblioteca. Isto foi feito por ter compreendido cartografia como " $[\ldots]$ a arte de construir um mapa sempre inacabado, aberto, composto de diferentes linhas, conectável, desmontável, reversível, suscetível de receber modificações constantemente" (DELEUZE; GUATTARI, 1996, p.21 apud DUARTE; CESTARI, 2017, p.2149). No primeiro ano de Iniciação Científica, conseguiu localizar cerca de 3000 obras publicadas entre 1910 e 1980 referentes ao ensino de matemática na Biblioteca Omar Catunda, tanto em nível superior, como em nível secundário. Para uma melhor visualização desse recorte temporal, tais obras foram divididas por décadas. Destas obras, fiz o mapeamento dos livros com teorias modernas da matemática que foram publicados no período proposto do plano de trabalho, isto é, de 1960 a 1968 . Na continuidade, nesse segundo ano de Iniciação Científica, foi construída novas categorizações para os livros didáticos a partir de seus respectivos títulos. Neste sentido, fiz uma nova tabela com as categorizações dos livros didáticos separando-os por níveis de ensino (secundário e superior). $\mathrm{O}$ nível superior tiveram as seguintes categorias: literaturas brasileiras, literaturas estrangeiras/traduzidas, editora e ano, as quais, analogamente, foram feitas também para o nível secundário. Nesse contexto, foi preciso também discutir pesquisas que envolviam livros didáticos e teorias modernas da matemática. Assim, os estudos de Bittencourt (2004), me levaram a compreender que a partir dos anos de 1980, pesquisadores começaram analisar o livro didático, por meio de uma perspectiva histórica, voltando o seu olhar para problemas relacionados aos conteúdos, aos processos de produção e a maneira que o livro era utilizado pelos professores e alunos. Tais análises tinham como objetivo situar o processo de mudanças e permanências do livro didático, quer seja como objeto cultural, quer seja pelos seus conteúdos e práticas pedagógicas. Dessa forma, para Bittencout (2004) o livro didático é um objeto cultural que, em diferentes situações, gera polêmicas e críticas, mas ainda assim é considerado um importante instrumento para a constituição da escolarização. Assim, os livros didáticos foram catalogados numa única perspectiva, ou seja, todos continham teorias modernas da matemática, por isso foram considerados documentos ou fontes históricas como sendo partes constituintes de uma cadeia de fontes do mesmo tipo, no sentido atribuído por Barros (2012). Para este historiador, a história serial faz uso de fontes homogêneas, as quais se referem a um período que diz respeitox a um problema a ser investigado, permitindo perceber, em um determinado recorte temporal, as permanências, as oscilações e as variações.

\section{RESULTADOS E/OU DISCUSSÃO (ou Análise e discussão dos resultados)}

Para fazer uma análise de minha pesquisa, foram feitas algumas indagações. Elas foram: Quais os autores que nesse período estavam vinculados a Universidade de São Paulo (USP)? Quais autores estavam vinculados ao Grupo Bourbaki nesse período? Quais palavras no título fazem menção à matemática moderna? A partir daí pude perceber que alguns autores daquele período (1960-1968) estavam vinculados a USP, como Omar Catunda, Edison Farah, Candido Lima, Luiz Henrique Jacy Monteiro e Benedito Castrucci, todos matemáticos brasileiros com participação ativa na institucionalização da matemática moderna, tanto no âmbito superior, como no nível secundário (LIMA, 2012). Além desses autores, tinham outros vinculados ao Grupo Bourbaki, como Jose Babini, Alexander Abian, Jean Alexandre Dieudonné, Charles Ehresmann, Robert E. Eicholz, Phares G. O'Daffer, Georges Papy, Frédérique Papy, Hans Hermes e Serge Lang. Nos livros categorizados havia uma predominância de campos considerados modernos da matemática, como álgebra moderna, álgebra linear e topologia, bem como 
se algumas de suas teorias, entre elas: teoria dos conjuntos; estruturas algébricas e teoria dos grupos.

\section{CONSIDERAÇÕES FINAIS (ou Conclusão)}

Por meio desses estudos percebi que houve grande circulação de livros internacionais literaturas estrangeiras - que eram produzidos por matemáticos que estavam atrelados às discussões da matemática moderna que passaram a vigora no ensino superior de diversas localidades, inclusive a brasileira, e que foram apropriadas também no ensino secundário de matemática. Houve também, nesse cenário, um grande número de livros produzidos nacionalmente, tanto no âmbito superior, quanto secundário, com apropriação das teorias modernas da matemática. Na Bahia, destacou-se os livros publicados pelo grupo liderado por Omar Catunda (1906-1986) e Martha Maria de Souza Dantas (1925-2011), que tiveram forte repercussão no ensino secundário de matemática baiano, principalmente, por meio de cursos voltados para a atualização dos professores que atuavam nesse nível escolar (LIMA; LANDO; FREIRE, 2013). Dessa forma, a cartografia dos livros didáticos pode ser útil para o desenvolvimento de novas pesquisas que têm como temática ou ponto de interseção a modernização da matemática no contexto brasileiro, em particular, na Bahia, ainda com muitas lacunas em sua historiografia, justamente pela amplitude de seu território e pela diversidade cultural e social, caracterizando apropriações muito próprias. Assim,, esta proposta de trabalho foi relevante para o Projeto de Pesquisa "As teorias modernas da matemática nos livros didáticos das instituições educacionais superiores e secundárias brasileiras e baianas", na medida em que abre novos horizontes para uma maior compreensão sobre as reformulações do ensino de matemática, as quais refletem ainda hoje não apenas na organização das disciplinas científicas para o ensino superior da matemática, mas também na organização dos conteúdos matemáticos referentes aos ensinos fundamental e médio.

\section{REFERÊNCIAS}

BITTENCOURT, Circe Maria Fernandes. Em foco: história, produção e memória do livro didático. Educação e Pesquisa, São Paulo, vol. 30, n. 3, [n.p.], set./dez. 2004.

BARROS, José D'Assunção. A história serial e história quantitativa no movimento dos Annales. História Revista, Goiania, v. 17, n.1, p. 203-207, jan./jun. 2012.

DUARTE, Juciara Rodrigues Rocha. CESTARI, Luiz Artur dos Santos. Cartografia: metodologia de pesquisa em currículo com filosofia da diferença. In: SEMINÁRIO NACIONAL, 6.,/ SEMINÁRIO INTERNACIONAL, POLÍTICAS PÚBLICAS, GESTÃO E PRÁXIS EDUCACIONAL, 2., 2017, Vitória da Conquista, Bahia-Brasil. [S.I.: s.n], 2017 v. 6, n. 6, p. 2148-2166.

GUIMARÃES, Henrique Manuel. Por uma matemática nova nas escolas secundárias perspectivas e orientações curriculares da matemática moderna. In: Matos, José Manuel; VALENTE, Wagner Rodrigues. (Org.) A Matemática Moderna nas escolas do Brasil e Portugal: primeiros estudos. São Paulo: Zapt Editora, 2007. p. 21-45.

LIMA, Eliene Barbosa. Matemática e matemáticos na Universidade de São Paulo: italianos, brasileiros e bourbakistas (1934-1958). 2012. 260f. Tese (Doutorado em Ensino, Filosofia e História das Ciências) - Instituto de Física, Universidade Federal da Bahia/Universidade Estadual de Feira de Santana, Salvador, 2012.

LIMA, Eliene. Barbosa; Dias, André Luis Mattedi. O Curso de análise matemática de Omar Catunda: uma forma peculiar de apropriação da análise matemática moderna. Revista Brasileira de História da Ciência, Rio de Janeiro, v. 3, n. 2, p. 211-230, jul./dez. 2010. 
LIMA, Eliene Barbosa et al. A institucionalização da matemática moderna nos currículos escolares ou a hegemonia da cultura matemática cientifica nas escolas. In: JORNADAS LATINOAMERICANAS DE ESTUDIOS SOCIALES DE LA CIENCIA Y TECNOLOGIA, 8., 2010, Buenos Aires. Anais... [S.I.: s.n], 2010, 1CD ROM, p. 119.

LIMA, E. B. Matemática e matemáticos na Universidade de São Paulo: italianos, brasileiros e bourbakistas (1934-1958). 2012. 260f. Tese (Doutorado em Ensino, Filosofia e História das Ciências) - Instituto de Física, Universidade Federal da Bahia/Universidade Estadual de Feira de Santana, Salvador, 2012.

LIMA, Eliene Barbosa; LANDO, Janice Cássia; FREIRE, Inês Angélica Andrade. A Coleção Didática Ensino Atualizado da Matemática: o guia do professor. In: CONGRESSO IBEROAMERICANO DE EDUCACIÓN MATEMÁTICA, 7., 2013. Actas...., Montevidéu, Uruguai, 2013.

LIMA, Eliene B. (Coord.). As teorias modernas da matemática nos livros didáticos das instituições educacionais superiores e secundárias brasileiras e baianas. Projeto de pesquisa submetido ao Edital FAPESB 11/2013 de Apoio à formação e articulação de redes de pesquisa no Estado da Bahia.

OLIVEIRA, Alice Mascarenhas. SILVA, Thalia de Jesus da. Os números naturais no livro ensino atualizado da matemática da $5^{\text {a }}$ série do primeiro grau. Feira de Santana, 2018. (No prelo). 